\title{
Examination in the Time of COVID-19-MCh Plastic Surgery Examination: How Did We Do It?
}

\author{
Shashank Chauhan ${ }^{1} \quad$ Suvashis Dash ${ }^{1, \odot} \quad$ Piyush Ranjan² ${ }^{2}$ Maneesh Singhal ${ }^{1}$ \\ ${ }^{1}$ Department of Plastic Reconstructive and Burns Surgery, All India \\ Institute of Medical Sciences, New Delhi, India \\ 2Department of Surgical Discipline, All India Institute of Medical \\ Sciences, New Delhi, India

\begin{abstract}
Address for correspondence Maneesh Singhal, MCh, FACS, FRCS, Department of Plastic Reconstructive and Burns Surgery, All India Institute of Medical Sciences, New Delhi 110029, India (e-mail:drmaneesh@gmail.com).
\end{abstract}

Indian J Plast Surg 2021;54:168-171.

Abstract
Keywords
- examination
- residency assessment
- COVID-19
- summative
assessment
- surgical education
- plastic surgery
education

Background Many aspects of life have been changed, after the starting of the pandemic. Modifications and improvisation in our day-to-day activities is now a new norm. During the pandemic period, continuation academic activities and conductance of examination is difficult but essential. We are sharing our experience of conductance of MCh examination during the pandemic and preparations made. This article also discussed the future of surgical assessment examination, use of technology in surgical assessment changing times.

Methods Procedural flow of the examination, Logistics and arrangements were planned and checked. Reliability and validity of questions were maintained by providing a similar set of questions and stepwise objective assessment. Assessment and feedback by the examinees and examiners on the pattern and conductance of examination were assessed by a Likert scale.

Results We found, $73 \%$ agreed examination patterns were able to test the knowledge fairly. While $80 \%$ believed the pattern was the same for all the candidates. All the stakeholders agreed the examination conducted in a Safe and stress-free atmosphere and use of technology helpful. Fifty- three \% agreed the case scenarios correctly simulate the clinical presentations. Lastly, $66 \%$ felt the examination process is adequate for summative assessment.

Conclusions It is vital to reflect regarding the need for a uniform module to handle changing scenarios keeping the integrity and quality of the examination. Interactive screen, mannequin, and 3D model will be useful in the examination. In future, standardized examination modules for the surgical trainees will be required to perform a comprehensive assessment.

\section{Introduction}

The coronavirus disease 2019 (COVID-19) pandemic has incapacitated many aspects of our life. Day-to-day activities, however, have been modified and adjusted to contain and prevent the disease spread. Similarly, the academic curriculum and the examinations have also faced many challenges during the COVID-19 pandemic. ${ }^{1}$ The MCh final examination is the exit

Dol https://doi.org/ 10.1055/s-0041-1731253 ISSN 0970-0358 examination or competency examination for a plastic surgery resident. It tests various factors such as knowledge, skill, decisions making, communication skill as well as approach to patients and patient care. ${ }^{2}$ At the same time, an examination should be reliable, valid without any bias, and conducted in a safe and quite environment. The conventional examinations are predominantly a type of summative assessment rather than a formative assessment. They are designed to test the abilities

(C) 2021. Association of Plastic Surgeons of India.

This is an open access article published by Thieme under the terms of the Creative Commons Attribution-NonDerivative-NonCommercial-License, permitting copying and reproduction so long as the original work is given appropriate credit. Contents may not be used for commercial purposes, or adapted, remixed, transformed or built upon. (https://creativecommons.org/licenses/by-nc-nd/4.0/).

Thieme Medical and Scientific Publishers Pvt. Ltd. A-12, 2nd Floor, Sector 2, Noida-201301 UP, India 
mentioned above in a candidate. In the conventional examinations for MCh degree, there are three broad headings for the residency assessment: (1) dissertations or thesis (2), theory examination (3), clinical/practical examination with viva voce. ${ }^{2}$

As we know, the core principles of infection control for COVID-19 demand social distancing, continuous mask use, and regular hand hygiene. ${ }^{3}$ In the time of this pandemic, there are many factors that prevent preforming all aspects of a conventional examination. In our institute, the outpatient department was not functional for 4 months; and regular inpatient admissions were also suspended. Gathering of large numbers of patient, relatives, residents, and examiners would not be ideal to maintain social distancing in preoccupied environment of examination. Hence, a solution to solve this puzzle lies in maintaining the above-mentioned core principles of COVID-19 prevention along with conducting a reliable, valid examination without any bias, in a pressure free, safe environment with minimal human error. We narrate our experience of conducting the MCh examination. One problem we faced was that testing was not very rampant at the of time of examination. Patient interaction/personal protective equipment in an examination is uncomfortable for the patients, examinee, and examiners. ${ }^{4}$ It is ethically wrong if anyone gets exposed during conduct of examination, be it patients, examinee, or examiner.

\section{Procedural Flow}

After discussion with the academic section of the institute, and concurrence of the examination section of institute, a detailed plan of conducting the examination was made. A preliminary discussion among the examiners was done on video conference to chalk out plan.

\section{Logistics and Arrangements}

1. Examination room-The examination was conducted in a large hall of size, $20 \times 20$ feet, with adequate ventilation and air conditioning with frequent air changes ( - Fig. 1). ${ }^{1}$

2. Food-The lunch and snacks during examination were provided, in individual clean, properly packed box. Social distancing was maintained during the lunch time. A separate open area was designated for eating.

3. Technology use-A large screen for display of the presentation, sound system, and microphone was installed in the examination hall.

4. Seating arrangement-The seating was done with at least 2-m distance between each seat ( - Fig. 1).

5. Rest room-The rest room contains sanitizers, paper towels that were well decontaminated in previous night.

6. Case scenarios-Ten sets of long case scenarios and 30 case of short case scenarios, as well as instruments, imaging in PowerPoint Presentation format were used. Each case was assigned a number.

7. Self-assessment-Preexamination self-assessment of all stakeholders of examination in a predetermined format was done every day in a WhatsApp group as well as android application-Epicollect5 (Oxford,Uk). ${ }^{2}$
8. Safety precautions-Following safety precautions were taken: social distancing, hand hygiene, and continuous use of N95, and cough/ sneeze etiquettes.

9. Postexamination measures-After the examination was concluded, all the persons involved in the examination were asked about presence of any symptoms so that testing and contact tracing could be done, if necessary. ${ }^{2}$

10. Others-Minimal exchange of articles and papers from handto-hand done to avoid fomite borne transmissions. Most of the communication made through the digital medium. Aarogya Setu Application was installed in personal mobile phone of all the personal involved in the examination.

\section{Conduct of the Examination}

As the institute policy was uniform, and it was not possible to implement different examination formats for different departments, hence, a uniform pattern was made for the examination. The theory examination was conducted in a large hall with social distancing of $>2 \mathrm{~m}$ between candidates for all subjects. The theory papers were scanned and converted into a digital format. These digital formats were stored confidentially. Evaluation of the papers were done by examiners on digital screens of laptops. The assessment scores were calculated and tabulated in digital forms; final form was printed and sent to the examination section confidentially. The dissertations were already assessed by the assessors before pandemic situation. For next batch, we are planning to submit and evaluate via electronically.

Our residents were residing in the campus of the institute; hence, the examination was concluded with ease. Places where residents travel from far off distances or from containment zones would face difficulties to conduct this kind of examination.

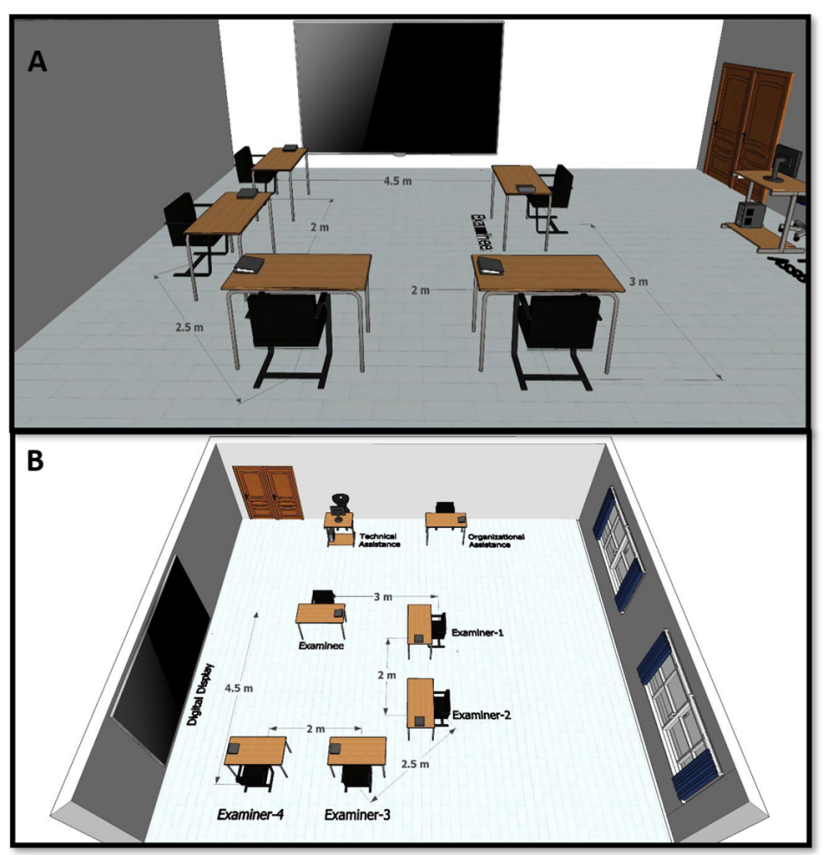

Fig. 1 Sitting arrangements of the examinees and examiners in the examination room: (A) Lateral view, and (B) aerial top view. 


\section{The Clinical Examination}

In conventional method of the practical/clinical examination, each candidate must take history and examination of actual patients and then appear in one long-case presentation and three short cases presentations apart from instruments, specimens, imaging, and operative viva. For the clinical part of examination, several challenges were faced by us. Due to the pandemic, we could not ask patients to take part in the examination. Hence, an alternative format of examination was done with help of digital format. We had two candidates appeared for the examination in this session. The candidates were asked to come in two batches for the examination. They were instructed to bring their own clinical tool kit for examination purpose. The mode of the examination was mixture of multimedia like pictures, short videos, and flash cards. We also prepared some mock history videos. Several moulages and mannequins were prepared for certain cases like soft tissue defects of leg.

\section{Question Patterns-Reliability and Validity}

The questions during the examination had objective assessment scores. Same marks were assigned to each step of answers. The cases and questions were decided before the examination, and same set of question was discussed (-Fig. 2).

\section{Assessment and Feedback by the Examinees and Examiners on Examination Pattern}

After the examination was over, the following question were asked to examinees and examiners, residents, and other faculty members, for improvement in format for the next session (-Table 1) (-Fig. 3).

- Has the examinee elicited proper history?

- Has the examinee elicited all positive points?

- Has the examinee described all negative points?

- Has the examinee demonstrated the rationality in his diagnosis?

- Has the examinee exhibit adequate clinical skill?

- Has the communication skill of the student is adequate?

- Has the examinee explained the investigations and rationality of needing them?

- Has the examinee provided adequate knowledge on management?

- Has the examinees exhibit adequate knowledge and reasoning?

- Is the overall performance of the examinees satisfactory in term of knowledge, rationality and approach?

Fig. 2 Question patterns-for comparing the reliability and validity of the examination.

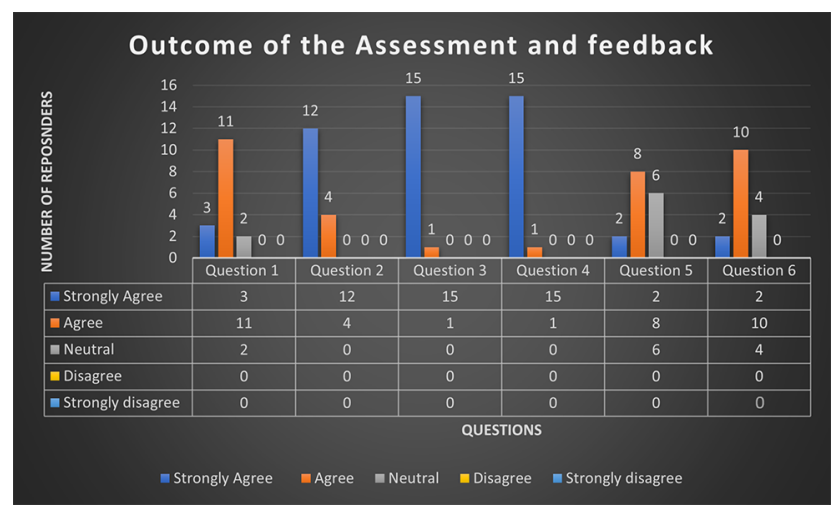

Fig. 3 Outcome of the questionaries assessment and feedback by the examinees and examiners, and faculties on the examination pattern by the stakeholders.

Table 1 Questionaries assessment and feedback by the examinees and examiners, and faculties on the examination pattern

\begin{tabular}{|l|l|l|}
\hline & Questions & $\begin{array}{l}\text { Score: } \\
1-5\end{array}$ \\
\hline 1 & $\begin{array}{l}\text { Was the examination pattern able to test the } \\
\text { knowledge? }\end{array}$ & \\
\hline 2 & $\begin{array}{l}\text { Was the examination pattern being same for both } \\
\text { the candidates? }\end{array}$ & \\
\hline 3 & $\begin{array}{l}\text { Was the examination conducted in a Safe and stress- } \\
\text { free atmosphere? }\end{array}$ & \\
\hline 4 & Was use of technology helpful in the examination? & \\
\hline 5 & $\begin{array}{l}\text { Were the case scenarios correctly simulate the } \\
\text { clinical presentations? }\end{array}$ & $\begin{array}{l}\text { Do you feel the examination process is adequate for } \\
\text { summative assessment? }\end{array}$ \\
\hline 6
\end{tabular}

Likert scale-strongly agree-5, agree-4, neutral-3, do not agree-2, strongly disagree-1.

\section{Conclusion}

The computer-based examination or digital examination showcases a realm of unmeasured potential. There is gradual evolution of these collective digital or computer-based assessments. It has propagated from simple true or false question to much advanced derivatives. ${ }^{3}$ The testing dimensions have also expanded exponentially that is good point for surgical education. In the time of pandemic, use of technology helped us to perform a well-organized examination in a safe environment that is vital.

The shortcomings of the digital examination are lack of patient, doctor communication skill and history elicitation, approach to patient, some deficiency in three-dimensional (3D) planning of reconstruction, technology dependence, etc.

The positive take outs from the format are safety and protection in COVID-19 environment by maintenance of social distancing, avoidance of direct patient contact, display of good quality and wide variety of image, instruments, and specimens. 


\section{Future Directions}

We used remotely-based patient to provide history over video conference so that patient interaction and history elicitation can also be tested. Use of 3D case simulators for 3D reconstruction planning is very lucrative to use for testing reconstructive plans and teaching in plastic surgery education. Use of multimedia question will add variety to the knowledge test. ${ }^{5,6}$ However, this is prime importance that before introduction of any new technology/platform, some precondition of the candidates should be done to mentally prepare for the examination. New things might appear, as the computers have been used for many years to perform the role of examiner to assess, but these are based on the prefilled data written in complex codes. But with the advent of machine learning and artificial intelligence, this part of the examination is now possible for a computer to perform easily in future. ${ }^{7-10}$

\section{What We Have Learnt and Would Want to Implement for Next Session?}

- Clinical assessment examination assesses knowledge, rational thinking, and skills of a candidate, which in the present scenario maybe difficult access only by virtual method.

- Use of technology is changing the pattern of examination and in future it will become very common. Physical presence of patients in the examination may not be required in future.

- Interactive screen with drawing, mannequin, and 3D model will be able to access further aspects of the examination.

- The pandemic removed the barrier of using technology in education and examination.

- In future, more standardized method of examination modules for the surgical trainees will be required to perform a comprehensive assessment.

\section{Conflict of Interest}

None.

\section{References}

1 https://www.who.int/news-room/q-a-detail/coronavirus-disease-covid-19-ventilation-and-air-conditioning\#: : tex$\mathrm{t}=$ Heating\%2C\%20ventilation\%20and\%20air,maintained\%2C\% 20and\%20cleaned. Accessed April 9, 2021

2 SahaS, PrakashP,SinghalS, ChauhanS, Singhal M, Chandrashekar S. Mobile app-based contact tracing during COVID-19-simple and without recall bias. Indian J Surg 2021;1-3:1-3 Epub ahead of print 10.1007/s12262-021-02735-z

3 Coronavirus in India. How life can change after lockdown [internet]. Available from: https://www.indiatoday.in/ mail-today/story/coronavirus-in-india-how-life-can-changeafter-lockdown-1676554-2020-05-11. Accessed April 9, 2021

4 Academic syllabus AIIMS [internet]. Available at from: https:// www.aiims.edu/aiims/academic/aiims-syllabus/Syllabus\%20 -\%20DM\%20\%20M\%20Ch.pdf. Accessed April 9, 2021

5 Coronavirus Disease. 2019 (COVID-19)- prevent-getting-sick [internet]. Available from: https://www.cdc.gov/coronavirus/2019-ncov/prevent-getting-sick/index.html. Accessed April 9, 2021

6 Stewart CL, Thornblade LWM, Diamond DJ, Fong Y. Melstrom LG. Personal Protective Equipment and COVID-19. Ann Surg 2020;272:132-138

7 Sun Z.3D printing in medicine: current applications and future directions. Quant Imaging Med Surg 2018;8(11):1069-1077

8 Satava RM, The Future of Surgical Simulation. Incomprehensive Healthcare Simulation: Surgery and Surgical Subspecialties. Cham: Springer; 2019 379-387

9 Kapadia MR, DaRosa DA, MacRae HM, Dunnington GL. Current assessment and future directions of surgical skills laboratories. J Surg Educ 2007;64(5):260-265

10 El Shallaly GE, Mekki AM. Use of computer-based clinical examination to assess medical students in surgery. Educ Health (Abingdon) 2012;25(3):148-152 